\title{
Bird harvesting practices and knowledge, risk perceptions, and attitudes regarding avian influenza among Canadian First Nations subsistence hunters: implications for influenza pandemic plans
}

\author{
Nadia A Charania ${ }^{1 *}$, lan D Martin ${ }^{1,2}$, Eric N Liberda ${ }^{3}$, Richard Meldrum ${ }^{3}$ and Leonard JS Tsuji ${ }^{1,2}$
}

\begin{abstract}
Background: There is concern of avian influenza virus (AIV) infections in humans. Subsistence hunters may be a potential risk group for AIV infections as they frequently come into close contact with wild birds and the aquatic habitats of birds while harvesting. This study aimed to examine if knowledge and risk perception of avian influenza influenced the use of protective measures and attitudes about hunting influenza-infected birds among subsistence hunters.

Methods: Using a community-based participatory research approach, a cross-sectional survey was conducted with current subsistence hunters $(n=106)$ residing in a remote and isolated First Nations community in northern Ontario, Canada from November 10-25, 2013. Simple descriptive statistics, cross-tabulations, and analysis of variance (ANOVA) were used to examine the distributions and relationships between variables. Written responses were deductively analyzed.

Results: ANOVA showed that males hunted significantly more birds per year than did females $\left(F_{1,96}=12.1 ; p=0.001\right)$ and that those who hunted significantly more days per year did not perceive a risk of AlV infection $\left(F_{1,94}=4.4 ; p=0.040\right)$. Hunters engaged in bird harvesting practices that could expose them to AlVs, namely by cleaning, plucking, and gutting birds and having direct contact with water. It was reported that $18(17.0 \%)$ hunters wore gloves and $2(1.9 \%)$ hunters wore goggles while processing birds. The majority of hunters washed their hands $(n=105 ; 99.1 \%)$ and sanitized their equipment $(n=69 ; 65.1 \%)$ after processing birds. More than half of the participants reported being aware of avian influenza, while almost one third perceived a risk of AlV infection while harvesting birds. Participants aware of avian influenza were more likely to perceive a risk of AIV infection while harvesting birds. Our results suggest that knowledge positively influenced the use of a recommended protective measure. Regarding attitudes, the frequency of participants who would cease harvesting birds was highest if avian influenza was detected in regional birds ( $n=55 ; 51.9 \%)$.

Conclusions: Our study indicated a need for more education about avian influenza and precautionary behaviours that are culturally-appropriate. First Nations subsistence hunters should be considered an avian influenza risk group and have associated special considerations included in future influenza pandemic plans.
\end{abstract}

Keywords: Avian influenza, Birds, Wild game, First Nations, Canada, Subsistence hunting, Harvesting, Pandemic plans, Risk perception

\footnotetext{
* Correspondence: ncharani@uwaterloo.ca

'Department of Environment and Resource Studies, University of Waterloo,

200 University Avenue West, N2L 3G1 Waterloo, Ontario, Canada

Full list of author information is available at the end of the article
} 


\section{Background}

Influenza A viruses may cause pandemics at unpredictable, irregular intervals resulting in devastating social and economic effects worldwide [1]. Wild aquatic birds in the orders Anseriformes and Charadriiformes are the natural hosts for influenza A viruses; these viruses have generally remained in evolutionary stasis and are usually non-pathogenic in wild birds [2,3]. Most avian influenza viruses (AIVs) primarily replicate in the intestinal tract of wild birds and are spread amongst birds via an indirect fecal-oral route involving contaminated aquatic habitats [4]. Humans who are directly exposed to the tissues, secretions, and excretions of infected birds or water contaminated with bird feces can become infected themselves $[2,4,5]$. The transmission of an AIV from a bird to a human has significant pandemic potential as it may result in the direct introduction of a novel virus strain or allow for the creation of a novel virus strain via reassortment $[3,5]$.

The transmission of AIVs from birds to humans depends on many factors, such as the susceptibility of humans to the virus and the frequency and type of contact [2,5]. Most AIVs are generally inefficient in infecting humans; however, there have been documented cases of AIVs transmitting directly from infected birds to humans [6,7]. During the 1997 Hong Kong "bird flu" incident, there was demonstrated transmission of highly pathogenic avian influenza (HPAI) A virus (H5N1) from infected domesticated chickens to humans [3]. More recently, some Asian countries have reported human infections of avian influenza A virus (H7N9) with most patients having a history of exposure to live poultry in wet markets [8]. As such, most pandemic plans include special considerations (e.g., enhanced surveillance, prioritization for vaccination, and antiviral prophylaxis) for avian influenza risk groups that include humans who come in close, frequent contact with domestic birds, such as farmers, poultry farm workers, veterinarians, and livestock workers $[9,10]$.

Longitudinally migrating wild birds appear to play a primary role in influenza transmission and there is increased concern about the introduction of HPAI virus strains in North America from Eurasia, as migratory flyways around the world intersect [3,4]. Thus, bird hunters may also be at risk as hunting and processing practices directly expose them to the bodily fluids of wild birds and water potentially contaminated with bird feces $[5,11]$. Although the risk of AIV infection while hunting and processing wild birds is assumed to be very low [5], transmission has been previously reported. One study reported serologic evidence of past AIV infection in a recreational duck hunter and two wildlife professionals, inferring direct transmission of AIVs from wild birds to humans [12]. Another study reported that recreational waterfowl hunters were eight times more likely to be exposed to avian influenza-infected wildlife compared to occupationally-exposed people and the general public [13]. A study conducted in rural Iowa, USA, reported that participants who hunted wild birds had increased antibody titers against avian $\mathrm{H} 7$ influenza virus [14]. Further, in the Republic of Azerbaijan, HPAI H5N1 infection in humans is suspected to be linked to defeathering infected wild swans (Cygnus) [15].

Since handling wild birds and having contact with the aquatic habitats of wild birds are potential transmission pathways for AIV infections in hunters, it is important to better understand hunters' knowledge and risk perceptions of avian influenza and include special considerations in pandemic plans. This is particularly important for some Canadian Aboriginal (First Nations, Inuit, and Métis) populations whose hunting of wild birds represents subsistence harvesting as opposed to a recreational activity [16]. Herein, subsistence harvesting will refer collectively to activities associated with hunting, fishing, trapping, and gathering of animals and other food for personal, family, and community consumption $[17,18]$. The practice of subsistence harvesting for some Canadian Aboriginal populations, such as the Cree First Nations of the Mushkegowuk region, is culturally and economically important with the majority of hunters harvesting wild birds $[17,19]$. Traditional land-based harvesting activities are economically valuable for the region and can reduce external economic dependence [17]. Moreover, as there are many physical, nutritional, and social benefits of this practice, it is a vital, wellestablished component of health and well-being in Canadian Aboriginal communities [20]. For instance, as Canadian Aboriginal populations, particularly those residing in geographically remote and isolated communities, experience a high prevalence of household food insecurity [21,22], subsistence harvesting can provide an important source of healthy traditional foods and lessen the reliance on costly market foods.

The potential of AIV infection while hunting and harvesting wild birds varies with geographical areas, seasons, and specific activities [5,11,12]. Moreover, previous studies have shown that knowledge and risk perception of avian influenza can positively influence compliance with recommended protective health behaviours $[23,24]$. We conducted a cross-sectional survey of the bird harvesting practices and knowledge, risk perceptions, and attitudes regarding avian influenza among Canadian First Nations subsistence hunters. The purpose of this study was to examine if knowledge and risk perception of avian influenza influenced the use of personal protection measures and attitudes about hunting influenza-infected birds. The implications for addressing the special considerations of Canadian First Nations subsistence hunters in pandemic plans will be discussed. 


\section{Methods}

\section{Community-based participatory research approach}

The present study employed a community-based participatory research (CBPR) approach since the hallmark principles of CBPR can foster the engagement of Aboriginal populations and participatory methods have previously been a successful approach to partnering with Aboriginal communities [25-27]. As such, the research topic was locally relevant as it stemmed from previous research conducted in the region that explored culturally-appropriate measures to mitigate the effects of an influenza pandemic in the setting of a remote and isolated Canadian First Nations community [28]. Residents of the study community expressed questions and concerns about the transmission potential of AIVs from influenza-infected wild birds to subsistence hunters. Thus, the present study was specifically developed and conducted to address the identified questions and concerns.

Following a CBPR approach, collaboration occurred throughout the research process between the researchers and a community-based advisory group (CBAG) comprised of two community representatives from the study community [29-31]. The two members of the CBAG were of First Nations heritage and were particularly interested in the topic at hand and desired to be involved. The CBAG helped design the study and was part of the iterative process of developing the survey questions and layout. The CBAG also provided input during the data analysis process, on the interpretation of results, and aided with disseminating the results to the community. CBPR endeavors aim to use the knowledge generated to achieve action-oriented outcomes for the involved community $[29,32]$. At the request of the CBAG, the results of this study were disseminated via an oral presentation to community members during a lunch-and-learn activity in June 2014. An information sheet explaining avian influenza and recommended precautionary behaviours created by Health Canada was distributed to attendees [33]. Information about emerging avian influenzas that currently are of pandemic concern and the information sheet were also incorporated into the community's influenza pandemic plan as a newly created appendix section.

Approval to conduct this research was granted by the Office of Research Ethics at the University of Waterloo (ORE \#16534), and was supported by the Band Council (locally elected First Nations government body) of the involved community.

\section{Study area, population, and data collection}

The study community (name omitted for anonymity purposes) is considered remote (i.e., nearest service center with year-round road access is located over 350 kilometers away) and isolated (i.e., accessible only by airplanes yearround) [10]. The Cree First Nations community belongs to the Mushkegowuk region which is located in northern Ontario, Canada along the western shores of James Bay and the southern portion of Hudson Bay $[17,19]$. The region is a productive wildlife area and the majority of hunters partake in the spring and fall bird harvests [34].

The cross-sectional survey was conducted in English (as suggested by the CBAG) from November 10-25, 2013. The time period was chosen to maximize participation, as most hunters would have returned from fall hunting activities. The survey was based on previous literature [11] and was developed in collaboration with the CBAG to ensure that it adequately addressed the objectives of the study and was culturally-appropriate. The survey employed closed-ended questions to gain a better understanding of First Nations hunters' general harvesting practices, knowledge and risk perception of avian influenza, and attitudes about hunting influenza-infected birds. Open-ended questions were also included to allow for participants to describe their risk perceptions of AIV infection while harvesting birds as well as any additional concerns. Basic demographic questions to record the age and sex of participants were also included.

Community First Nations subsistence hunters were invited to participate by the lead author (NAC) and a local community research assistant during individual meetings. The research assistant was of First Nations descent and a prominent Elder in the community. Being fluent in the Cree language, the assistant acted as a Cree translator upon request by the survey respondents. A current community housing list (updated in November 2013) which recorded all known community members living in First Nations (Band) households was used by the research assistant to identify eligible participants. Contemporary harvesting practices in the region typically involve multiple short trips versus traditional long trips [34]. To include as many hunters as possible from the study community, eligible participants were defined as current hunters, a group which included "intensive", "active", and "occasional" hunters (for definitions, see [17]). In addition to being a current hunter, participants were required to be First Nations (Band member), an adult (18 years old and over), and available to complete the survey in person during the study period to be eligible. Both male and female hunters were approached as it is widely recognized in Cree First Nations that both sexes play an important role while subsistence harvesting [35].

When approached, the participants were provided with an information/recruitment letter and the study was explained in English or Cree as required. Informed verbal consent was obtained, being culturally appropriate for the region $[31,36]$. Incentives were not offered for participation. As participants preferred to complete the survey alone on their own time, a convenient time and location was arranged to collect the completed survey. Up to five 
follow-up visits and new survey copies were provided if the survey was not completed at the specified time and if the person was still interested in participating.

\section{Data management and analyses}

Collected surveys were coded by an identification number to maintain confidentiality of the participants. The CBAG was consulted to determine how to code inexact responses. Of note, it was decided that if a participant responded with a range of numbers, the median value was recorded. If a participant selected all of the possible response options or only provided a written response, the result was recorded as missing data. In instances where a pattern was observed amongst participants' written responses, the responses were coded according to newly created response options approved by the CBAG to maintain the integrity of the data.

Sample size for individual statistical analyses varied from 88 to 106, as not all participants answered each survey question; thus, presented percentages may not always equal $100 \%$ owing to missing data. Simple descriptive statistics were used to examine the distributions of variables pertaining to general harvesting practices, knowledge and risk perception of avian influenza, and attitudes about hunting influenza-infected birds. Cross-tabulations, as $2 \times 2$ contingency analyses, were used to examine the relationships between each of the main effects of sex, awareness of avian influenza, and risk perception of AIV infection by precautionary behaviours and attitudes about hunting influenza-infected birds. In instances where the expected cell count was less than five, the Fisher's Exact Test was used in preference to the Pearson chi-square test. Absolute values greater than 1.96 of the adjusted standard residual (ASR) indicated a significant departure from the expected count and therefore considered to be a major contributor to the observed chi-square result.

The influence of outlier values for continuous dependent variables (age, years of hunting, days of hunting per year, birds hunted per year) was examined using boxplots of raw and $\log$ transformed data. Owing to the presence of outlier values, we log-transformed values for days of hunting and number of birds hunted per year to satisfy the homogeneity of variance assumption of analysis of variance (ANOVA). It was decided that one individual's improbable response for number of birds hunted per year should be removed as it continued to distort the results. Also, one individual's response for years of hunting was recorded as missing data since the response did not reflect the age of the participant. Differences in mean values of these dependent variables between groups for sex, awareness of avian influenza, and risk perception of AIV infection were examined using ANOVA. Statistical results were considered to be significant at $\mathrm{p}<$ 0.05. Data analyses were carried out using SPSS version 22 (SPSS Inc., Chicago, Illinois, U.S.A).
Written responses to the two open-ended questions and any additional comments were manually transcribed verbatim into electronic format to facilitate organization and coding. Qualitative coding of the transcribed data was conducted using QSR NVivo version 9.2 (QSR International Pty Ltd., Doncaster, Victoria, Australia). Responses were deductively analyzed following a template organizing approach using the survey questions as a coding template $[37,38]$. Analyzing the data was an iterative process conducted multiple times by the lead author (NAC) and findings were presented to the CBAG as a way of member checking to verify the results [37].

\section{Results}

A total of 173 participants in the censused community were deemed eligible to participate given the inclusion criteria and of these, 126 received surveys, for a $73 \%$ contact rate. Of the 126 distributed surveys, 106 completed surveys were returned, representing an $84 \%$ cooperation rate. Overall, a response rate of $61 \%$ was achieved. Of the 106 community members that participated in the survey, 80 (75.5\%) were male and 26 (24.5\%) were female. The untransformed demographic and harvesting characteristics of the participants are presented in Table 1.

All who responded participated in the spring/summer hunting activities $(\mathrm{n}=105 ; 99.1 \%)$ with fewer hunters participating during the fall $(\mathrm{n}=57 ; 53.8 \%)$ and winter $(\mathrm{n}=16 ; 15.1 \%)$ seasons. During these hunts, $98.1 \%$ of participants hunted Canada geese (Branta canadensis), 88.7\% hunted various species of ducks (Anatinae), 69.8\% hunted lesser snow geese (Anser c. caerulescens, also referred to as wavies), and $43.4 \%$ hunted species of shorebirds (Charadriiformes).

While hunting, the majority of participants reported having direct contact with water $(\mathrm{n}=89 ; 84.0 \%)$. Bird harvesting practices were generally similar whether camping in the bush or at home; thus, only results pertaining to camping in the bush are presented. In the bush, most hunters processed the birds themselves $(n=72 ; 67.9 \%)$ or a family member was involved $(n=67 ; 63.2 \%)$. Most hunters partook in all of the bird processing activities in the bush; the percentage of participants who reported cleaning, plucking, and gutting the birds were $74.5 \%$, $94.3 \%$, and $77.4 \%$ respectively. Regarding the use of precautionary measures while processing birds in the bush, it was reported that $18(17.0 \%)$ hunters wore gloves and 2 (1.9\%) hunters wore goggles. In the bush, the majority of hunters washed their hands $(\mathrm{n}=105 ; 99.1 \%)$ and sanitized their equipment $(n=69 ; 65.1 \%)$ after processing birds. Moreover, about half of the participants $(n=50 ; 47.2 \%)$ reported receiving the annual vaccination against seasonal human influenza viruses (Figure 1).

The total frequency and percentage of participants' knowledge of avian influenza, risk perception of AIV 
Table 1 Demographic and harvesting characteristics of Canadian First Nations subsistence hunters residing in the study community $(n=106)$, November 10-25, 2013

\begin{tabular}{|c|c|c|c|c|c|}
\hline & $\mathbf{n}$ & Minimum & Maximum & Mean & Std. deviation \\
\hline \multicolumn{6}{|l|}{ Demographic information } \\
\hline Age & 92 & 18 & 76 & 43.3 & 12.9 \\
\hline \multicolumn{6}{|l|}{ Harvesting characteristics } \\
\hline Years of hunting & 99 & 1 & 65 & 27.2 & 14.0 \\
\hline Days of hunting per year & 105 & 1 & 200 & 26.2 & 30.5 \\
\hline Number of birds hunted per year & 100 & 0 & 200 & 42.6 & 40.6 \\
\hline
\end{tabular}

infection, and attitudes about hunting influenza-infected birds are presented in Table 2. Approximately half of the participants $(\mathrm{n}=56 ; 52.8 \%)$ reported being generally aware of avian influenza, but few were aware of the signs and symptoms of avian influenza in birds $(\mathrm{n}=16$; $15.1 \%)$ or humans $(\mathrm{n}=9 ; 8.5 \%)$.

Some participants $(\mathrm{n}=29 ; 27.4 \%)$ perceived a risk of contracting avian influenza while harvesting birds.

"Just wondering every time we go out hunting geese in the spring, if any of the geese that come in [the] spring are carrying the flu" (Participant \#41).

"Yes there is a risk [be]cause the birds [are] from the South ... who knows what they'll catch out there" (Participant \#103).

"It will concern me if the bird flu is here on our Land and I wouldn't be sure about hunting birds"

(Participant \#42).

On the other hand, many participants did not perceive a risk of AIV infection while harvesting birds, since local regional birds were not perceived to be infected with avian influenza.
"I thought there was only bird flu in Asia ..."

(Participant \#24).

"If birds were sick, I don't think they would make it this far [North]" (Participant \#70).

"No reports that bird flu has arrived in this area and people are not getting sick" (Participant \#36).

Detection of avian influenza in wild birds in nearby geographic areas would reportedly influence the participants' harvesting behaviour. The frequency of participants who would cease harvesting birds was highest if avian influenza was detected in local regional birds $(\mathrm{n}=$ $55 ; 51.9 \%)$. It was reported that 45 (42.5\%) respondents would stop hunting if avian influenza was found in birds from within the Province of Ontario, and 43 (40.6\%) respondents would stop hunting if the virus was found in North American birds. For all of the aforementioned scenarios, some participants added written responses indicating that they were not sure if they would stop hunting and requested relevant information. The majority of respondents also were interested in receiving information about avian influenza transmission $(\mathrm{n}=83 ; 78.3 \%)$, flyways of migrating birds $(n=79 ; 74.5 \%)$, and precautions to minimize exposure $(n=82 ; 77.4 \%)$.

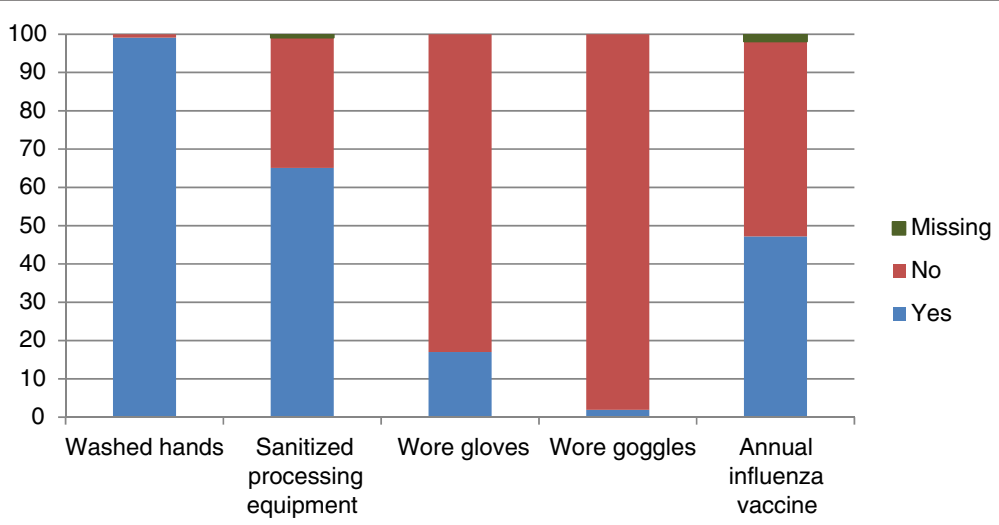

Figure 1 Compliance with recommended protective health measures among Canadian First Nations subsistence hunters residing in the study community $(n=106)$, November 10-25, 2013. 
Table 2 Frequency and percentage ${ }^{a}$ of knowledge of avian influenza, risk perception of avian influenza virus infection, and attitudes about hunting influenza-infected birds among Canadian First Nations subsistence hunters residing in the study community $(n=106)$, November 10-25, 2013

\begin{tabular}{|c|c|c|c|c|c|c|}
\hline & \multicolumn{2}{|c|}{ All hunters } & \multicolumn{2}{|c|}{ Males } & \multicolumn{2}{|c|}{ Females } \\
\hline & No (\%) & Yes (\%) & No (\%) & Yes (\%) & No (\%) & Yes (\%) \\
\hline \multicolumn{7}{|l|}{ Knowledge } \\
\hline Aware of avian influenza & $49(46.2)$ & $56(52.8)$ & $37(46.3)$ & $42(52.5)$ & $12(46.2)$ & $14(53.8)$ \\
\hline Aware of signs and symptoms of avian influenza in birds & $89(84.0)$ & $16(15.1)$ & $67(83.8)$ & $12(15.0)$ & $22(84.6)$ & $4(15.4)$ \\
\hline Aware of signs and symptoms of avian influenza in humans & 95 (89.6) & $9(8.5)$ & $74(92.5)$ & $4(5.0)$ & $21(80.8)$ & $5(19.2)$ \\
\hline \multicolumn{7}{|l|}{ Risk perception } \\
\hline Perceived risk of avian influenza virus infection & $68(64.2)$ & $29(27.4)$ & $52(65.0)$ & $23(28.8)$ & $16(61.5)$ & $6(23.1)$ \\
\hline \multicolumn{7}{|l|}{ Attitudes } \\
\hline Cease hunting if avian influenza detected in North American birds & $60(56.6)$ & $43(40.6)$ & $49(61.3)$ & $29(36.3)$ & $11(42.3)$ & $14(53.8)$ \\
\hline Cease hunting if avian influenza detected in Province of Ontario birds & $54(50.9)$ & $45(42.5)$ & $45(56.3)$ & $30(37.5)$ & $9(34.6)$ & $15(57.7)$ \\
\hline Cease hunting if avian influenza detected in Regional birds & $46(43.4)$ & $55(51.9)$ & $39(48.8)$ & $37(46.3)$ & $7(26.9)$ & $18(69.2)$ \\
\hline
\end{tabular}

ANOVA showed that males hunted significantly more birds per year than did females $\left(F_{1,96}=12.1 ; p=0.001\right.$; Figure 2). No significant difference in mean values of age, years of hunting, and days of hunting per year was observed between males and females. ANOVA did not identify any significant differences in mean values of age, years of hunting, days of hunting per year, and number of birds hunted per year between those who were or were not aware of avian influenza. However, ANOVA did show that those who hunted significantly more days per year did not perceive a risk of AIV infection while harvesting birds $\left(\mathrm{F}_{1,94}=4.4 ; \mathrm{p}=0.040\right.$; Figure 2$)$. No significant difference in mean values of age, years of hunting, and number of birds hunted per year was observed between those who did or did not perceive a risk of AIV infection.
For all participants, in $2 \times 2$ contingency analysis, a significant dependence was observed between awareness of avian influenza and risk perception of AIV infection (Pearson $\chi^{2}=4.456 ; p=0.035$ ) (Table 3). An ASR of +2.1 indicated that participants aware of avian influenza were significantly more likely to perceive a risk of AIV infection while harvesting birds. No significant dependence was seen between sex and awareness of avian influenza or sex and perceived risk of AIV infection.

A significant dependence was observed between sex and the attitude of ceasing hunting if influenza was detected in regional birds (Pearson $\chi^{2}=4.123 ; p=0.042$ ) (Table 4). An ASR of -2.0 indicted that males were significantly less likely to stop hunting if influenza was detected in the local regional birds. No significant dependence was observed
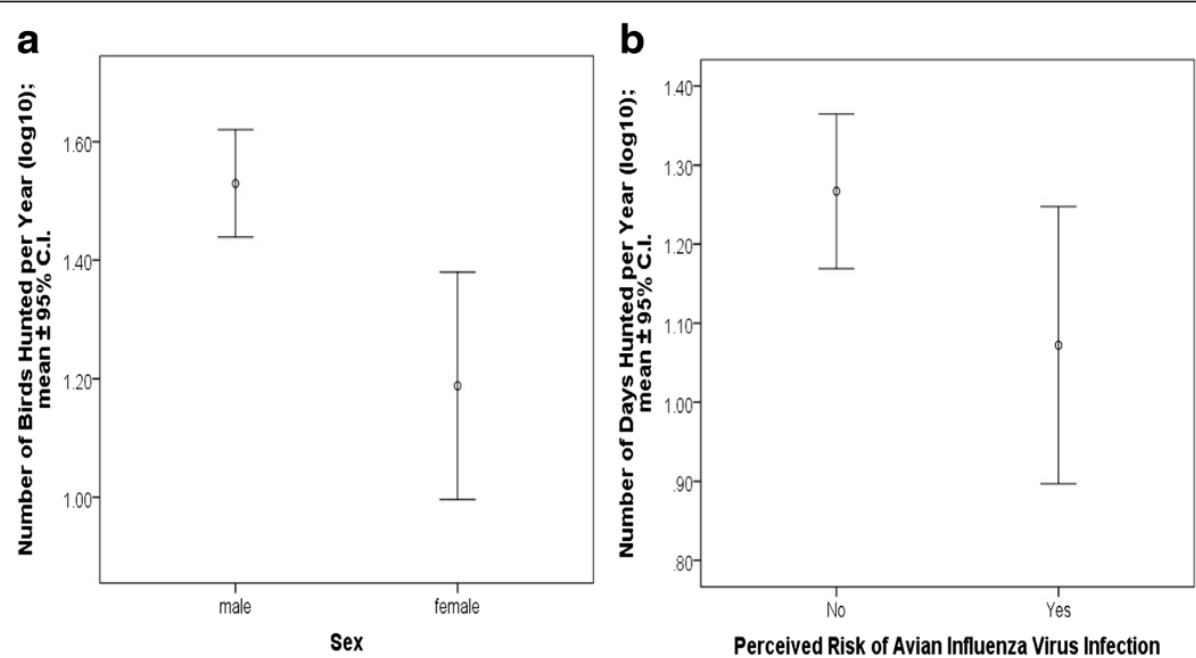

Figure 2 Analysis of variance for number of birds hunted per year by males and females (a) and number of days hunted per year by perceived risk of avian influenza virus infection while harvesting birds (b) among Canadian First Nations subsistence hunters residing in the study community $(n=106)$, November 10-25, 2013. 
Table 3 Cross-tabulation for awareness of avian influenza by risk perception of avian influenza infection while harvesting birds among Canadian First Nations subsistence hunters residing in the study community ( $n=106)$, November 10-25, 2013

\begin{tabular}{|c|c|c|c|c|c|}
\hline & & & \multicolumn{2}{|c|}{$\begin{array}{c}\text { Perceived risk of avian } \\
\text { influenza infection } \\
\text { while harvesting birds }\end{array}$} & \multirow[t]{2}{*}{ Total } \\
\hline & & & No & Yes & \\
\hline \multirow{4}{*}{$\begin{array}{l}\text { Aware of avian } \\
\text { influenza }\end{array}$} & \multirow[t]{2}{*}{ No } & Count & 37 & 9 & 46 \\
\hline & & Adjusted Residual & +2.1 & -2.1 & \\
\hline & \multirow[t]{2}{*}{ Yes } & Count & 31 & 20 & 51 \\
\hline & & Adjusted Residual & -2.1 & +2.1 & \\
\hline
\end{tabular}

between the two main effects of awareness of avian influenza and perceived risk of AIV infection by attitudes about hunting influenza-infected birds.

A significant dependence also was observed between awareness of avian influenza and the precautionary behaviour of sanitizing equipment after processing birds while camping in the bush (Pearson $x^{2}=4.070 ; \mathrm{p}=$ 0.044) (Table 5). An ASR of +2.0 indicated that a significantly greater frequency of aware participants were among those who cleaned their bird processing equipment. No significant dependence was observed between awareness of avian influenza by any of the other recommended precautions to be used while harvesting birds. Moreover, no significant dependence was observed between the two main effects of sex and perceived risk of AIV infection by any of the precautionary behaviours.

\section{Discussion}

\section{Harvesting activities}

As mentioned, the potential of AIV infection while hunting and processing wild birds varies with specific practices, seasons, and geographical areas $[5,11,12]$. The hunters reported being in frequent contact with wild birds, as some participants hunted for more than 100 days per year and harvested up to 200 birds per year. Our findings indicated that First Nations subsistence hunters were involved in bird harvesting practices, such as processing

Table 4 Cross-tabulation for sex by cease hunting if influenza detected in Regional birds among Canadian First Nations subsistence hunters residing in the study community $(n=106)$, November 10-25, 2013

\begin{tabular}{|c|c|c|c|c|c|}
\hline & & & \multicolumn{2}{|c|}{$\begin{array}{l}\text { Cease hunting if influenza } \\
\text { detected in Regional birds }\end{array}$} & \multirow[t]{2}{*}{ Total } \\
\hline & & & No & Yes & \\
\hline \multirow[t]{4}{*}{ Sex } & Male & Count & 39 & 37 & 76 \\
\hline & & Adjusted Residual & +2.0 & -2.0 & \\
\hline & Female & Count & 7 & 18 & 25 \\
\hline & & Adjusted Residual & -2.0 & +2.0 & \\
\hline
\end{tabular}

Table 5 Cross-tabulation for awareness of avian influenza by sanitizing bird processing equipment in the bush among Canadian First Nations subsistence hunters residing in the study community $(n=106)$, November 10-25, 2013

\begin{tabular}{lllccc}
\hline & & & $\begin{array}{c}\text { Sanitize bird } \\
\text { processing } \\
\text { equipment } \\
\text { in the bush }\end{array}$ & \\
\cline { 3 - 4 } & & & Total \\
\hline Aware of avian influenza & No & Count & Yes & \\
\hline & Yes & Count & 21 & 27 & 48 \\
& & Adjusted Residual & -2.0 & +2.0 & \\
\hline
\end{tabular}

the birds and having direct contact with water in the bush, that pose an increased hazard to AIV infections among this subpopulation. The main proposed pathway of transmission of AIV to humans is close contact between the tissues, secretions, and excretions of an infected bird and the respiratory tract, gastrointestinal tract, or conjunctiva of a human [2,7,39]. Infected birds shed copious amounts of virus particles in their feces which can also contaminate the environment and bodies of water $[40,41]$. Our findings revealed that the majority of hunters had direct contact with water and cleaned, plucked, and gutted the wild birds themselves. If processing an influenzainfected wild bird in this manner, hunters may be exposed to virus-laden tissues, secretions, and excretions [2,5]. The use of personal protective equipment was not routine practice as most hunters did not wear gloves and goggles to protect themselves while processing birds. However, most hunters reported using other measures of personal protection, such as washing their hands and cleaning their equipment, which can limit post-harvest AIV exposure.

The timing of the hunters' bird harvesting activities in relation to when the prevalence peaks for AIVs and human influenza viruses is of particular interest. Similar to previous reports, our study revealed that the majority of hunters were involved in the spring and fall bird harvests $[16,19,34]$. The timing of these harvests is in relation to freeze-up and break-up events in the region which varies every year, but generally runs from April to October [42]. During these harvests, participants reported hunting migratory wild birds that are potential carriers of AIVs as all known influenza A virus subtypes have been identified in these birds [3,43]. For instance, in North American wild ducks, AIV prevalence peaks around late summer/early fall prior to south bound migration, with highest virus isolation rates reported in juvenile ducks $[44,45]$. On the other hand, previous studies have reported relatively low prevalence of AIVs in Canada geese regardless of the season $[45,46]$. Moreover, in Canada, the peak season of influenza A infection in humans typically runs from November to April [33]. Similar to another study, our 
results suggest that the possibility of co-infection with AIVs and human influenza viruses resulting in a reassortment event is unlikely as the timing of the hunters' potential exposure to AIVs is different from that of seasonal human influenza viruses [5].

Based on previous studies, the surveyed participants generally hunt for wild birds around the southwestern coast of Hudson Bay and the western coast of James Bay which is along the Mississippi migratory flyway $[3,34,47,48]$. Migratory flyways around the world intersect, particularly between eastern Eurasia and Alaska and between Europe and eastern North America, raising concerns about the exchange of AIVs between the Eurasian and American virus superfamilies [3,43]. Intercontinental exchange of entire AIV genomes has not yet been reported and Eurasian HPAI virus subtypes have not been previously detected in North American migratory birds [43,49]. However, reassortment events between the two lineages has been reported, notably in Alaska and along the northeastern coast of Canada [43,49-51]. These observations suggest that the introduction of a novel AIV is more likely to occur along the Pacific and Atlantic coasts of North America, but once introduced, it has been suggested that migration to major congregation sites may disperse the novel AIV across flyways [49,51,52].

\section{Awareness, risk perception, and attitudes}

Approximately half of our study participants were generally aware of avian influenza (52.8\%), which is lower than previous studies conducted with bird hunters in the USA (86\%) and poultry workers in Nigeria (67.1\%) and Italy $(63.8 \%)[11,23,53]$. Similar to a previous study, our findings indicated that a general awareness of avian influenza was more common among the surveyed bird hunters compared to knowledge of the signs and symptoms [11]. Previous studies conducted with high-risk populations in Thailand and Laos also reported limited knowledge of the key signs and symptoms of avian influenza $[54,55]$. Almost one third of surveyed participants perceived a risk of contracting avian influenza while hunting and processing birds which is similar to the values found in other studies $[24,56]$.

Our results revealed that the frequency of First Nations hunters who would cease harvesting birds increased as AIV was detected in more nearby geographic areas. This observation aligns with findings from a previous study; however, the percentage of hunters who would stop was relatively higher in our study as only $3 \%$ and $19 \%$ of active duck hunters in Georgia, USA reported that they would stop hunting if HPAI were found in duck populations in USA and the state of Georgia, respectively [11]. This result is interesting as harvesting activities are integral to First Nations' culture and an important source of healthy food, especially in communities experiencing food insecurity $[17,20,22]$.
Our findings suggested that being aware of avian influenza or perceiving a risk of AIV infection did not influence the hunters' decision to cease harvesting influenza-infected birds. However, those who were knowledgeable were more likely to clean their equipment after processing birds in the bush. This finding suggests that First Nations hunters are not only willing to use precautionary measures while harvesting birds, but that improving their knowledge level may lead to an increased use of recommended precautionary measures. Previous studies also found that knowledge and perception of risk was a significant determinant of greater compliance with recommended protective measures $[23,24]$. However, in our study, being knowledgeable or perceiving risk did not always result in greater use of protective measures. Moreover, in general, the limited use of gloves and goggles while processing harvested birds was noted. These observations may be explained by the protection motivation theory which states that complying with a recommended protective health behavior is influenced by risk perception as well as efficacy variables, including response efficacy (i.e., whether the recommended measure is effective) and self-efficacy (i.e., whether the person is capable of performing the recommended measure) [57-59]. According to this theory, risk perception will generate a willingness to act, but efficacy variables will determine whether the resulting action is adaptive or maladaptive $[57,58]$. In our study, those who perceived a risk may have doubted the effectiveness of recommended measures and/or had low self-efficacy owing to limited access to resources and ability to afford supplies required to implement the measures [60].

\section{Recommendations for influenza pandemic plans}

These data support previous findings which suggest that bird hunting and processing activities may potentially expose individuals to avian influenza [5,11-14]. Acknowledging the various benefits and cultural importance of subsistence harvesting $[17,20]$, while taking into account the increased hazard of potential AIV exposure in First Nations hunters, their inclusion as an avian influenza risk group with associated special considerations in pandemic plans seems warranted. The potential for a novel AIV to be introduced into an Aboriginal Canadian population is of great concern as they face many health disparities and are particularly susceptible to influenza and related complications [61]. Moreover, previous influenza pandemics have disproportionately impacted Aboriginal Canadians, especially those populations living in geographically remote communities, and reflected inadequacies in preparedness with regards to addressing their pre-existing inequalities and special needs during a pandemic [62-65]. 
Efforts should be directed towards improving education for First Nations hunters regarding avian influenza and the hazard posed by AIVs while harvesting wild birds. More specifically, our results indicated that educational endeavours should include information regarding the signs and symptoms of avian influenza, transmission dynamics, flyways of migrating birds, and recommended precautionary measures (Table 6). Accordingly, access to supplies required to comply with recommended protective measures, such as cleaning solutions and gloves, should be improved for First Nations subsistence hunters. Moreover, our findings suggested that detection of avian influenza in wild birds in nearby geographic areas would influence the participants' harvesting behaviour. Given this, we recommend that a culturally-appropriate communication system be implemented to promptly inform subsistence hunters and other community members of the findings and any associated recommendations.

\section{Study strengths and limitations}

To our knowledge, this is the first study to examine the knowledge and risk perceptions of avian influenza among Canadian First Nations subsistence hunters. The censused approach taken to select participants and the high contact and cooperation rates strengthen the assertion that our findings are representative of the study community. Also, in accordance with a CBPR approach, the CBAG was involved throughout the entire research process, thereby ensuring that the study was conducted in a culturally-appropriate manner and that the knowledge generated was used to directly benefit the involved community.
Despite the novelty and significance of our findings, some limitations of our study must be highlighted when interpreting our results. First, the analysis was based on a cross-sectional survey of self-reported data which may limit drawing definitive conclusions about the observed relationships. The biases in recalling and reporting cannot be entirely ruled out; however, to help alleviate the potential for biased responses, participants were assured that their responses would remain anonymous. Also, it is not possible to discern whether those who did not return the survey or refused to participate were different in any way from those who did participate. However, there is no obvious reason to suspect that non-respondents and people who chose not to participate were any different from the respondents.

Future research should examine the prevalence of AIVs, particularly those strains that are currently of concern to humans (e.g., H5, H7), in birds from within the Mushkegowuk Territory that are typically harvested. Also, analyzing the sera for antibodies against AIV subtypes would be helpful to evaluate if previous AIV infections occurred in First Nation subsistence hunters. Moreover, conducting a quantitative exposure assessment would provide information to help characterize the study population's exposure potential to AIVs. Lastly, previous research has noted that various barriers impede the effectiveness of implementing recommended pandemic mitigation measures [60]. Thus, future research should aim to understand if any barriers exist with regards to complying with recommended precautions to reduce exposure to AIVs while harvesting birds and if measures need to be adapted to be more context-specific and culturally-appropriate, while still maintaining the effectiveness of the measure.

Table 6 Recommended precautions for Canadian First Nations subsistence hunters to reduce exposure to avian influenza viruses while harvesting wild birds (adapted from [33])

Do not touch or eat sick birds or birds that have died for unknown reasons

Avoid touching the blood, secretions, or dropping of wild game birds

Do not rub your eyes, touch your face, eat, drink or smoke when processing wild game birds

Keep young children away when processing wild game birds and discourage them from playing in areas that could be contaminated with wild bird droppings

When preparing game, wash knives, tools, work surfaces, and other equipment with soap and warm water followed by a household bleach solution (0.5\% sodium hypochlorite)

Wear water-proof household gloves or disposable latex/plastic gloves when processing wild game birds

Wash gloves and hands (for at least 20 seconds) with soap and warm water immediately after you have finished processing game or cleaning equipment. If there is no water available, remove any dirt using a moist towlette, apply an alcohol based hand gel (between 60-90\% alcohol) and wash your hands with soap and water as soon as it is possible

Change clothes after handling wild game birds and keep soiled clothing and shoes in a sealed plastic bag until they can be washed

When cooking birds, the inside temperature should reach $85^{\circ} \mathrm{C}$ for whole birds or $74^{\circ} \mathrm{C}$ for bird parts (no visible pink meat and juice runs clear)

Never keep wild birds in your home or as pets

Receive the annual influenza vaccine

If you become sick while handling birds or shortly afterwards, see your doctor and inform your doctor that you have been in close contact with wild birds 


\section{Conclusions}

Our study aimed to gain an understanding of the bird harvesting practices and knowledge, risk perceptions, and attitudes regarding avian influenza among Canadian First Nations subsistence hunters and provide recommendations for pandemic plans. The findings herein indicated that First Nations subsistence hunters partook in some practices while harvesting wild birds that could potentially expose them to avian influenza, although appropriate levels of compliance with some protective measures were reported. More than half of the respondents were generally aware of avian influenza and almost one third perceived a risk of AIV infection while harvesting birds. Participants aware of avian influenza were more likely to perceive a risk of AIV infection while harvesting birds. Our results suggest that knowledge positively influenced the use of a recommended protective measure. Regarding attitudes about hunting influenza-infected birds, our results revealed that the frequency of First Nations hunters who would cease harvesting birds increased as AIV was detected in more nearby geographic areas.

Given that the potential exposure to AIVs while hunting is assumed to be low but the cultural importance of subsistence hunting high, our study indicated a need for more education about avian influenza and precautions First Nations hunters can take to reduce the possibility of AIV exposure while harvesting wild birds that are culturallyappropriate. We posit that First Nations hunters should be considered an avian influenza risk group and have associated special considerations included in pandemic plans.

\section{Competing interests}

The authors declare that they have no competing interests.

\section{Authors' contributions}

NAC contributed to the original concept and design of the study, participated in data collection, analyses and interpretation, and drafted the manuscript. IDM contributed to data analyses and interpretation, and manuscript drafts. ENL contributed to the design of the study and manuscript drafts. RM contributed to the design of the study and manuscript drafts. LJST contributed to the design of the study, data analyses and interpretation, and manuscript drafts. All authors read and approved the final manuscript.

\section{Acknowledgements}

The authors would like to thank the members of the community-based advisory group, the local research assistant, and all of the participants involved in the study for their invaluable contributions. This study was funded by the Canadian Institutes of Health Research (Institute of Aboriginal Peoples' Health), Aboriginal Affairs and Northern Development Canada (Northern Scientific Training Program), and the Vanier Canada Graduate Scholarship program.

\footnotetext{
Author details

${ }^{1}$ Department of Environment and Resource Studies, University of Waterloo, 200 University Avenue West, N2L 3G1 Waterloo, Ontario, Canada. ${ }^{2}$ Department of Physical \& Environmental Sciences, University of Toronto Scarborough, 1265 Military Trail, M1C 1A4 Toronto, Ontario, Canada. ${ }^{3}$ School of Occupational and Public Health, Ryerson University, 350 Victoria Street, POD 247H, M5B 2K3 Toronto, Ontario, Canada.
}

Received: 7 July 2014 Accepted: 13 October 2014

Published: 28 October 2014

\section{References}

1. World Health Organization: Pandemic influenza preparedness and response: a WHO guidance document. 2009. http://whqlibdoc.who.int/ publications/2009/9789241547680_eng.pdf.

2. Riedel S: Crossing the species barrier: the threat of an avian influenza pandemic. Proc (Bayl Univ Med Cent) 2006, 19(1):16-20.

3. Olsen B, Munster VJ, Wallensten A, Waldenström J, Osterhaus ADME, Fouchier RAM: Global patterns of influenza $A$ virus in wild birds. Science 2006, 312(5772):384-388.

4. Webster RG: The importance of animal influenza for human disease. Vaccine 2002, 20(suppl):S16-S20.

5. Dórea FC, Cole DJ, Stallknecht DE: Quantitative exposure assessment of waterfowl hunters to avian influenza viruses. Epidemiol Infect 2013, 141(5):1039-1049.

6. Beigel JH, Farrar J, Han AM, Hayden FG, Hyer R, De Jong MD, Lochindarat S, Tien NTK, Hien NT, Hien TT, Nicoll A, Touch S, Yuen KY: Avian influenza A (H5N1) infection in humans. New Engl J Med 2005, 353(13):1374-1385.

7. Peiris JSM, De Jong MD, Guan Y: Avian influenza virus (H5N1): a threat to human health. Clin Microbiol Rev 2007, 20(2):243-267.

8. World Health Organization: WHO risk assessment: human infections with avian influenza $A(H 7 N 9)$ virus. 2014. http://www.who.int/influenza/ human_animal_interface/influenza_h7n9/140225_H7N9RA_for_web_ 20140306FM.pdf?ua=1

9. World Health Organization: Comparative analysis of national pandemic influenza preparedness plans. 2011. http://www.who.int/influenza/ resources/documents/comparative_analysis_php_2011_en.pdf?ua=1.

10. Public Health Agency of Canada: The Canadian pandemic influenza plan for the health sector. 2011. http://www.phac-aspc.gc.ca/cpip-pclcpi/indexeng.php.

11. Dishman H, Stallknecht D, Cole D: Duck hunters' perceptions of risk for avian influenza, Georgia, USA. Emerg Infect Dis 2010, 16(8):1279-1281.

12. Gill JS, Webby R, Gilchrist MJR, Gray GC: Avian influenza among waterfowl hunters and wildlife processionals. Emerg Infect Dis 2006, 12(8):1284-1286.

13. Siembieda J, Johnson CK, Boyce W, Sandrock C, Cardona C: Risk for avian influenza virus exposure at human-wildlife interface. Emerg Infect Dis 2008, 14(7):1151-1153.

14. Gray GC, McCarthy T, Capuano AW, Setterquist SF, Alavanja MC, Lynch CF: Evidence for avian influenza A infections among lowa's agricultural workers. Influenza Other Respir Viruses 2008, 2(2):61-69.

15. Gilsdorf A, Boxall N, Gasimov V, Agayev I, Mammadzade F, Ursu P, Gasimov E, Brown C, Mardel S, Jankovic D, Pimentel G, Amir Ayoub I, Maher Labib Elassal E, Salvi C, Legros D, Pessoa Da Silva C, Hay A, Andraghetti R, Rodier $G$, Ganter B: Two clusters of human infection with influenza $A / H 5 N 1$ virus in the Republic of Azerbaijan, February-March 2006. Eurosurveillance 2006, 11(5):122-126.

16. Tsuji LS: Mandatory use of non-toxic shotshell: cultural and economic concerns for Mushkegowuk Cree. CJNS 1998, 1:19-36.

17. Berkes F, George PJ, Preston RJ, Hughes A, Turner J, Cummins BD: Wildlife harvesting and sustainable regional native economy in the Hudson and James Bay lowland, Ontario. Arctic 1994, 47(4):350-360.

18. Tam BY, Gough WA, Edwards V, Tsuji LS: The impact of climate change on the well-being and lifestyle of a First Nation community in the western James Bay region. Can Geogr-Geogr Can 2013, 57(4):441-456.

19. Tsuji LUS, Nieboer E: A question of sustainability in Cree harvesting practices: the seasons, technological and cultural changes in the western James Bay region of northern Ontario, Canada. CJNS 1999, 1:169-192.

20. Van Oostdam J, Donaldson SG, Feeley M, Arnold D, Ayotte P, Bondy G, Chan L, Dewailly É, Furgal CM, Kuhnlein H, Loring E, Muckle G, Myles E, Receveur O, Tracy B, Gill U, Kalhok S: Human health implications of environmental contaminants in Arctic Canada: a review. Sci Total Environ 2005, 1(351-352):165-246.

21. Hlimi T, Skinner K, Hanning RM, Martin ID, Tsuji LJS: Traditional food consumption behaviour and concern with environmental contaminants among Cree schoolchildren of the Mushkegowuk territory. IJCH 2012, 71:17344.

22. Skinner K, Hanning RM, Tsuji LS: Prevalence and severity of household food insecurity of First Nations people living in an on-reserve, sub-arctic community within the Mushkegowuk Territory. Public Health Nutr 2014, 17(1):31-39.

23. Abbate R, Di Giuseppe G, Marinelli P, Angelillo IF: Knowledge, attitudes, and practices of avian influenza, poultry workers, Italy. Emerg Infect Dis 2006, 12(11):1762-1765. 
24. Di Giuseppe G, Abbate R, Albano L, Marinelli P, Angelillo IF: A survey of knowledge, attitudes and practices towards avian influenza in an adult population of Italy. BMC Infect Dis 2008, 8:36.

25. St Denis V: Community-based participatory research: aspects of the concept relevant for practice. In Critical Strategies for Social Research. Edited by Carroll WK. Toronto: Canadian Scholars' Press; 2004:292-302.

26. Macaulay AC, Delormier T, McComber AM, Cross EJ, Potvin LP, Paradis G, Kirby RL, Saad-Haddad C, Desrosiers S: Participatory research with native community of Kahnawake creates innovative code of research ethics. Can J Public Health 1998, 89(2):105-108.

27. Davis SM, Reid R: Practicing participatory research in American Indian communities. Am J Clin Nutr 1999, 69(suppl):S755-S759.

28. Charania NA, Tsuji LJS: Recommended mitigation measures for an influenza pandemic in remote and isolated First Nations communities of Ontario, Canada: a community-based participatory research approach. IIPJ 2014, 5(3):1-22.

29. Israel BA, Eng E, Schulz AJ, Parker EA: Introduction to methods in community-based participatory research for health. In Methods in Community-Based Participatory Research for Health. Edited by Israel BA, Eng E, Schulz AJ, Parker EA. San Francisco: John Wiley \& Sons, Publishers; 2005:3-26

30. Charania NA, Tsuji LJS: Government bodies and their influence on the $2009 \mathrm{H} 1 \mathrm{~N} 1$ health sector pandemic response in remote and isolated First Nation communities of sub-arctic Ontario, Canada. RRH 2011, 11 (3):1781.

31. Kirby AM, Lévesque L, Wabano V, Robertson-Wilson J: Perceived community environment and physical activity involvement in a northern-rural Aboriginal community. Int J Behav Nutr Phys Act 2007, 4:63.

32. Israel BA, Schulz AJ, Parker EA, Becker AB, Allen AJ III, Guzman JR: Critical issues in developing and following CBPR principles. In Community-Based Participatory Research for Health: From Process to Outcomes. 2nd edition. Edited by Minkler M, Wallerstein N. San Francisco: John \& Wiley Sons, Publishers; 2008:47-66.

33. Health Canada: Influenza (the flu). 2011. http://www.hc-sc.gc.ca/fniahspnia/diseases-maladies/influenza/index-eng.php.

34. Berkes F, Hughes A, George PJ, Preston RJ, Cummins BD, Turner J: The persistence of Aboriginal land use: fish and wildlife harvest areas in the Hudson and James Bay lowlandm, Ontario. Arctic 1995, 48(1):81-93.

35. Ohmagari K, Berkes F: Transmission of Indigenous knowledge and bush skills among the western James Bay Cree women of subarctic Canada. Hum Ecol 1997, 25(2):197-222.

36. Skinner K, Hanning RM, Tsuji LJS: Barriers and supports for healthy eating and physical activity for First Nation youths in northern Canada. IJCH 2006, 65(2):148-161.

37. Bryman A: Social Research Methods. New York: Oxford University Press; 2001.

38. Crabtree BF, Miller WL: Using codes and code manuals: a template organizing style of interpretation. In Doing Qualitative Research. 2nd edition. Edited by Crabtree BF, Miller WL. Newbury Park: Sage Publications; 1999:163-177.

39. Weber TP, Stilianakis NI: Inactivation of influenza A viruses in the environment and modes of transmission: a critical review. J Infection 2008, 57(5):361-373.

40. Nazir J, Haumacher R, Ike A, Stumpf P, Böhm R, Marschang RE: Long-term study on tenacity of avian influenza viruses in water (distilled water, normal saline, and surface water) at different temperatures. Avian Dis 2010, 54(suppl 1):720-724.

41. Zarkov IS, Urumova VS: Effects of humidity and temperature on avian influenza virus $\mathrm{H} 6 \mathrm{~N} 2$ persistence in faecal samples form experimentally infected ducks (Anas platyrynchos). Revue Méd Vét 2013, 164(7):343-347.

42. McDonald ML, Arragutainaq L, Novalinga Z: Voices from the Bay: Traditional Ecological Knowledge of Inuit and Cree in the Hudson Bay Bioregion. Ottawa and Sanikiluaq: Canadian Arctic Resources Committee, Municipality of Sanikiluaq; 1997.

43. Krauss S, Obert CA, Franks J, Walker D, Jones K, Seiler P, Niles L, Paul Pryor S, Obenauer JC, Naeve CW, Widjaja L, Webby RJ, Webster RG: Influenza in migratory birds and evidence of limited intercontinental virus exchange. PLOS Pathog 2007, 3(11):1684-1693.

44. Stallknecht DE, Shane SM: Host range of avian influenza virus in free-living birds. Vet Res Commun 1988, 12(2-3):125-141.

45. Hinshaw VS, Wood JM, Webster RG, Deibel R, Turner B: Circulation of influenza viruses and paramyxoviruses in waterfowl originating from two different areas of North America. B World Health Organ 1985, 63(4):711-719.

46. Harris MT, Brown JD, Goekjian VH, Page Luttrell M, Poulson RL, Wilcox BR, Swayne DE, Stallknecht DE: Canada Geese and the epidemiology of avian influenza viruses. J Wildlife Dis 2010, 46(3):981-987.

47. Hanson HC, Currie C: The kill of wild geese by the natives of the Hudson-James Bay region. Arctic 1957, 10(4):221-229.

48. Krauss S, Walker D, Paul Pryor S, Niles L, Chenghong L, Hinshaw VS, Webster RG: Influenza A viruses of migrating wild aquatic birds in North America. Vector-Borne Zoonot 2004, 4(3):177-189.

49. Koehler AV, Pearce JM, Flint PL, Christian Franson J, Ip HS: Genetic evidence of intercontinental movement of avian influenza in a migratory bird: the northern pintail (Anas acuta). Mol Ecol 2008, 17(21):4754-4762.

50. Ip HS, Flint PL, Christian Franson J, Dusek RJ, Derksen DV, Gill RE Jr, Ely CR, Pearce JM, Lanctot RB, Matsuoka SM, Irons DB, Fischer JB, Oates RM, Petersen MR, Fondell TF, Rocque DA, Pedersen JC, Rothe TC: Prevalence of influenza A viruses in wild migratory birds in Alaska: patterns of variation in detection at a crossroads of intercontinental flyways. Virol J 2008, 5:71.

51. Hall JS, TeSlaa JL, Nashold SW, Halpin RA, Stockwell T, Wentworth DE, Dugan V, Ip HS: Evolution of a reassortant North American gull influenza virus lineage: drift, shift and stability. Virol J 2013, 10:179.

52. Bahl J, Krauss S, Kühnert D, Fourment M, Raven G, Paul Pryor S, Niles LJ, Danner A, Walker D, Mendenhall IH, Su YCF, Dugan VG, Halpin RA, Stockwell TB, Webby RJ, Wentworth DE, Drummond AJ, Smith GJD, Webster RG: Influenza $A$ virus migration and persistence in North American wild birds. PLOS Pathog 2013, 9(8):1-12.

53. Fasina OF, Disschop SPR, Ibironke AA, Meseko CA: Avian influenza risk perception among poultry workers, Nigeria. Emerg Infect Dis 2009, 15(4):616-617

54. Maton T, Butraporn P, Kaewkangwal J, Fungladda W: Avian influenza protection knowledge, awareness, and behaviors in a high-risk population in Suphan Buri province, Thailand. Southeast Asian J Trop Med Public Health 2007, 38(3):560-568.

55. Barennes H, Martinez-Aussel B, Vongphrachanh P, Strobel M: Avian influenza risk perceptions, Laos. Emerg Infect Dis 2007, 13(7):1126-1128.

56. Fielding R, Lan WWT, Ho EYY, Hing Lam T, Hedley AJ, Leung GM: Avian influenza risk perception, Hong Kong. Emerg Infect Dis 2005, 11(5):677-682.

57. Roger R: A protection motivation theory of fear appeals and attitude change. J Psychol 1975, 91(1):93-114.

58. Floyd D, Prentice-Dunn S, Rogers R: A meta-analysis of research on protection motivation theory. J App/ Soc Psychol 2000, 30(2):407-429.

59. De Zwart O, Veldhuijzen IK, Elam G, Aro AR, Abraham T, Bishop GD, Hendrik Richardus J, Brug J: Avian influenza risk perception, Europe and Asia. Emerg Infect Dis 2007, 13(2):290-293.

60. Charania NA, Tsuji LJS: Assessing the effectiveness and feasibility of implementing mitigation measures for an influenza pandemic in remote and isolated First Nations communities: a qualitative community-based participatory research approach. RRH 2013, 13(4):2566.

61. MacMillan HL, MacMillan AB, Offord DR, Dingle JL: Aboriginal health. Can Med Assoc J 1996, 155(11):1569-1578.

62. Kermode-Scott B: Canada has world's highest rate of confirmed cases of A/H1N1, with Aboriginal people hardest hit. Br Med J 2009, 339:b2746.

63. Kumar A, Zarychanski R, Pinto R, Cook DJ, Marshall J, Lacroix J, Stelfox T, Bagshaw S, Choong K, Lamontagne F, Turgeon AF, Lapinsky S, Ahern SP, Smith O, Siddiqui F, Jouvet $\mathrm{P}$, Khwaja K, McIntyre L, Menon K, Hutchison J, Hornstein D, Joffe A, Lauzier F, Singh J, Karachi T, Wiebe K, Olafson K, Ramsey C, Sharma S, Dodek P, et al: Critically ill patients with 2009 influenza $A(H 1 N 1)$ infection in Canada. JAMA 2009, 302(17):1872-1879.

64. Barker K: Canadian First Nations experience with H1N1: new lessons or perennial issues? Int J Tuberc Lung D 2010, 14(2):130.

65. Spence N, White JP: Scientific certainty in a time of uncertainty: predicting vulnerability of Canada's First Nations to pandemic H1N1/09. IIPJ 2010, 1(1):1-36

\section{doi:10.1186/1471-2458-14-1113}

Cite this article as: Charania et al:: Bird harvesting practices and knowledge, risk perceptions, and attitudes regarding avian influenza among Canadian First Nations subsistence hunters: implications for influenza pandemic plans. BMC Public Health 2014 14:1113. 